\title{
Daño vascular inducido en el pie equino por veneno de la serpiente Bothrops diporus
}

\author{
Teibler, G.P.'; Bustillo, S. ${ }^{4}$; Dubiel, C.J. ${ }^{1}$; Bogado, E.F.2 ; Maruñak, S.L. ${ }^{3}$ \\ Cátedras de Farmacología ${ }^{1}$, Cínica de Grandes Animales² y Bioquímica ${ }^{3}$, Facultad de Ciencias Veterinarias, \\ Universidad Nacional del Nordeste (UNNE), Cabral 2139, Corrientes, Argentina. ${ }^{4}$ Cátedra de \\ Química Biológica I, Fac.Ciencias Exactas, UNNE. E-mail: pteibler@gmail.com
}

\begin{abstract}
Resumen
Teibler, G.P.; Bustillo, S.; Dubiel, C.J.; Bogado, E.F.; Maruñak, S.L.: Daño vascular inducido en el pie equino por veneno de la serpiente Bothrops diporus. Rev. vet. 28: 1, 41-46, 2017. Con el objeto de avalar la sensibilidad del veneno ofídico sobre la densa red vascular que irriga el pie equino, se analizaron los efectos in vitro de $50 \mu \mathrm{g}$ de veneno, a través de biopsias de talones de 5 equinos de raza indefinida. Las muestras se incubaron en placas de cultivo celular conteniendo medio DMEM (Dulbecco's Modified Eagle's Medium). Un grupo de muestras operó como control y otro fue tratado con veneno, en estufa a $37^{\circ} \mathrm{C}$, con $5 \%$ de dióxido de carbono y $95 \%$ de humedad durante 24 y $48 \mathrm{~h}$. Concluida la incubación, las muestras se fijaron en formaldehído bufferado y se procesaron con las técnicas clásicas para histopatología, siendo teñidas con HyE y PAS para su observación en microscopio óptico. Las muestras destinadas a microscopía electrónica de transmisión (MET) fueron tratadas por el método clásico. En los cortes coloreados (HyE) las arteriolas presentaron desprendimiento de células endoteliales, los núcleos fueron fuertemente basófilos, aumentados de tamaño y de forma redondeada. Las metaarteriolas presentaron disrupción de la pared vascular y separación de las capas que forman su túnica media, con macrocariosis endotelial. Las vénulas mostraron los mismos daños, manifestándose además la ruptura de la pared vascular. La técnica PAS permitió localizar daños a nivel de la membrana basal de las células endoteliales de todos los vasos sanguíneos estudiados. La MET reveló mitocondrias que resaltaban en puntos determinados del citoplasma, con aumento de la electrodensidad. Las vesículas pinocíticas citoplasmáticas mostraron tamaño variable, con distribución irregular; las uniones intercelulares estaban alteradas. El modelo experimental de biopsia, como cultivo primario, permitió el estudio de alteraciones en la red vascular inducidas por toxinas de veneno de serpiente, constituyendo una herramienta valiosa considerando que no afecta la salud del animal.
\end{abstract}

Palabras claves: equino, veneno de serpiente, biopsia del pie, cultivo celular, microscopía óptica y electrónica.

\begin{abstract}
Teibler G.P.; Bustillo, S.; Dubiel, C.J.; Bogado, E.F.; Maruñak, S.L.: Vascular damage in horse hoof caused by Bothorps diporus snake venom. Rev. vet. 28: 1, 41-46, 2016. In this work we study the effects caused by the venom of Bothrops diporus on the dense vascular network that supplies the equine foot. In order to analyze the in vitro effects, samples of the knee area of five horse hoofs were incubated in DMEM (Dulbecco's Modified Eagle's Medium) plus 50 ug snake venom in cell culture plates. Samples incubated with DMEM and without venom were considered as controls. All the samples were incubated at $37{ }^{\circ} \mathrm{C}$ in a $5 \%$ carbon dioxide atmosphere, $95 \%$ humidity during 24 and 48 hours. After incubation samples were fixed in buffered formaldehyde and processed according to the classical techniques for histopathology, stained with hematoxylin and eosin (H\&E) and periodic acid-Schiff (PAS) for observation under optic microscope. Samples for transmission electron microscopy (TEM) were treated by the classic method. Samples stained with H\&E showed arteriolar endothelial cell detachment, strong basophilic, enlarged and rounded nuclei. The metarterioles had disruption of the vascular wall and separation of the layers of the tunica media with endothelial macrocariosis. Venules showed the same damage as well as disrup-
\end{abstract}


tion of the wall vessel. PAS staining showed damage at the basal membrane of endothelial cells of all the vessels under study. TEM showed mitochondria in certain parts of the cytoplasm with increased electrodensity. Pinocytic citoplasmic vesicles showed variable size, with irregular distribution, with altered cell junctions. The experimental model using biopsy as the primary culture allowed the study of alterations in the vascular network induced by the toxins present in the venom. Thus, it can be considered a useful tool considering as it does not affect the animal's health.

Key words: equine, snake venom, foot biopsy, cell culture, optical and transmission electron microscopy.

\section{INTRODUCCIÓN}

La región del pie equino, en su punto más distal, reúne a la dermis y una modificación de la epidermis, el casco, formando la unión dermo-epidérmica. El estuche córneo que recubre a la tercera falange se caracteriza por ser avascular y, para la adecuada nutrición e intercambio gaseoso de sus células basales, depende de la irrigación proporcionada por el tejido dérmico ${ }^{18,19}$.

La unión dermo-epidérmica o engranaje queratopodofiloso, se establece así entre las láminas epidérmicas (primarias y secundarias) y láminas dérmicas (primarias y secundarias). En la microcirculación del tejido laminar dérmico se encuentran numerosas anastomosis arteriovenosas $\left(500 / \mathrm{cm}^{2}\right)$, que surgen de ramas de las arterias axiales ${ }^{16,20}$. Las anastomosis unen arterias y venas sin pasar por los capilares, constituyendo una vía alternativa para la circulación de la sangre ${ }^{13}$.

De esta manera, cuando el pie alcanza una temperatura crítica, la lenta circulación de mantenimiento de la dermis pasa inmediatamente a una circulación rápida de calentamiento mediante la apertura refleja de las múltiples anastomosis arteriovenosas ${ }^{20}$. Ello demuestra la importancia de los vasos sanguíneos del pie equino, particularmente compleja en la zona de talones, de quien depende la eficiencia de trabajo del animal, constituyendo una región anatómica muy vascular y -por su accesibilidad- favorable para obtener biopsias destinadas al estudio de posibles efectos adversos inducidos por sustancias tóxicas.

Diferentes etiologías con acción sistémica pueden alterar dicha red vascular u otras estructuras de la unión dermo-epidérmica del pie ${ }^{1,12}$, como las intoxicaciones causadas por veneno de serpientes, específicamente las del género Bothrops ${ }^{5,27}$. Estos efectos son inducidos por una variedad de componentes como fosfolipasa $\mathrm{A}_{2}$ y metaloproteinasas (hemorraginas), entre otros ${ }^{8,9}$.

Las hemorraginas afectan al endotelio capilar, predisponiendo a hemorragias in situ y al pasar al torrente vascular este efecto puede presentarse en distintos ór$\operatorname{ganos}^{2,7,9}$. Recientemente se ha demostrado la acción sinérgica entre las proteínas contenidas en los venenos, razón por la cual los efectos causados se deben a la acción conjunta de sus componentes. No obstante el efecto de potenciación, es sabido que cada proteína cumple un rol definido en la intoxicación ${ }^{11}$.
El pie equino cuenta con un denso paquete de arterias laminares interconectadas, ramas abaxiales cortas y capilares interconectados en dirección abaxial ${ }^{21}$ , que lo convierten en un buen modelo experimental para la realización de ensayos tendientes a determinar mecanismos de acción de toxinas in vitro sobre la red vascular. Aunque los venenos botrópicos han sido ampliamente estudiados, es de interés complementar su caracterización extendiendo los estudios a su impacto en el sistema hemostático, especialmente porque en Argentina las serpientes son responsables de un gran número de accidentes ${ }^{22}$.

El objetivo de este trabajo fue analizar los efectos que causa el veneno entero de Bothrops diporus sobre la densa red vascular que irriga al pie equino, a través de biopsias obtenidas en la zona de talones, sin comprometer la vida del animal, avalados por los antecedentes ya mencionados que demuestran su sensibilidad a la acción de toxinas ofídicas. El modelo propuesto es válido para el estudio de la acción de proteínas aisladas de los venenos, para luego interpretar la fisiopatología de la intoxicación.

\section{MATERIAL Y MÉTODOS}

Obtención y conservación del veneno. Se obtuvo un pool de veneno de especimenes adultos de Bothrops diporus capturados en el nordeste argentino y mantenidos en un serpentario de la ciudad de Corrientes, Argentina. El veneno fue desecado a temperatura ambiente y mantenido a $-20^{\circ} \mathrm{C}$. Al momento de su uso, fue disuelto con solución salina de buffer fosfato $\mathrm{pH} 7,2$.

Toma de muestras (biopsias) de pies equinos. La toma de muestra se realizó, a partir de los talones del pie de cinco equinos de raza indefinida, de 3 a 15 años de edad, en el quirófano de la Facultad de Ciencias Veterinarias-UNNE, previo lavado intenso de los miembros, mediante biopsias ${ }^{15}$. Los animales fueron tranquilizados con maleato de acepromacina $1 \%$ a dosis de $0,05 \mathrm{mg} / \mathrm{kg}$. Luego se realizó el adelgazamiento del casco a nivel de la región de talones utilizando una escofina. Posteriormente se procedió al bloqueo abaxial mediante anestesia perineural con lidocaína al $2 \%$ a razón de $3 \mathrm{ml}$. Previa antisepsia de la zona, se efectuó una incisión de $0,5 \times 1 \mathrm{~cm}$ con bisturí hoja $\mathrm{N}^{\circ} 24$. A continuación se realizó vendaje compresivo 
previa colocación de torunda de gasa estéril embebida con Povidona-iodo 3\%. El tratamiento posquirúrgico consistió en el cambio de vendajes cada $12 \mathrm{~h}$ y antibioticoterapia con penicilina-estreptomicina (22.000 UI/ $\mathrm{kg}$ ) combinada con analgésicos (fenilbutazona a dosis de $2,2 \mathrm{mg} / \mathrm{kg}$. cada $24 \mathrm{~h}$ ).

Procesamiento de las muestras. Las muestras obtenidas fueron colectadas en recipiente estéril e inmediatamente reducidas a fragmentos más pequeños de aproximadamente $0,5 \times 0,1 \mathrm{~cm}$ (12 muestras por animal), incluyendo en el corte al menos 4 láminas primarias. Posteriormente se lavaron con solución fisiológica mediante pasajes sucesivos en cajas de Petri estériles, bajo flujo laminar, totalizando 5 pasajes o lavados ${ }^{17}$. Las muestras fueron colocadas en placa de cultivo celular Cellstar ${ }^{\circledR}$ de 12 Wells, conteniendo medio de cultivo DMEM. Para las incubaciones se estableció un grupo control, el cual fue incubado en Wells conteniendo solamente el medio de cultivo y un grupo tratado incubado con el agregado de $50 \mu \mathrm{g}$ de veneno entero de $B$. diporus en estufa de $37^{\circ} \mathrm{C}, 5 \%$ de dióxido de carbono y $95 \%$ de humedad, durante 24 y 48 hs.

Microscopía óptica y electrónica de transmisión. Concluida la incubación, las muestras se fijaron en formaldehído bufferado al $10 \%$ por el término de 24 h para luego ser procesadas con las técnicas clásicas para histopatología y teñidas con Hematoxilina Eosina (HyE) y Acido Peryodico de Schiff (PAS). Las muestras destinadas a microscopía de transmisión fueron fijadas en glutaraldehído al $2,5 \%$ en buffer fosfato 0,1 $\mathrm{M}, \mathrm{pH} 7,4$ post-fijado en tetróxido de osmio al $1 \%$ en buffer fosfato $0,1 \mathrm{M}, \mathrm{pH} 7,4$; lavado en solución de sucrosa. Luego los tejidos fueron deshidratados en etanol en concentración creciente y finalmente embebidos en epon (resina). Se efectuaron cortes ultrafinos que fueron observados con microscopio electrónico de transmisión JEOL 1210 TEM con GATAN double-tilt stage.

\section{RESULTADOS}

Resultados histopatológicos. Las muestras control, coloreados con hematoxilina-eosina, al ser observadas a través de microscopía óptica mostraron vasos sanguíneos con características normales, con paredes constituidas por una túnica íntima, de epitelio plano simple, túnica intermedia y adventicia. La técnica de PAS permitió además poner de manifiesto la integridad y continuidad de la membrana basal, por lo cual resultó más significativa para el análisis histopatológico de las muestras (Figuras A y B).

En los cortes histológicos correspondientes a la incubación de los explants (muestras de tejido vivo) con $50 \mu \mathrm{g}$ de veneno de $B$. diporus, incubados durante 24 $\mathrm{h}$ y coloreados con hematoxilina-eosina, se observaron arteriolas que presentaban desprendimiento de algunas de sus células endoteliales, mientras otras aparecían parcialmente desprendidas de su membrana basal. Los núcleos se encontraban fuertemente basófilos, aumentados de tamaño y de forma redondeada, muchos de

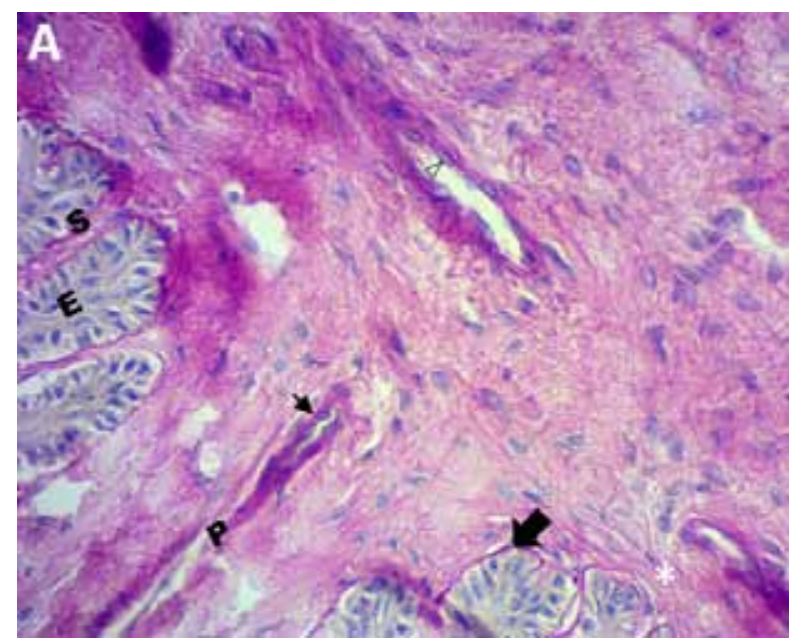

Figura A. Unión dermo-epidérmica de pie equino control. Se observan láminas epidérmicas primarias $(\mathrm{P})$ y secundarias (E, S). Nótese la membrana basal continua unida a las células epidérmicas basales (flecha negra grande), vénulas de paredes delgadas con endotelio normal (punta de flecha), de núcleo basófilo apoyada sobre la membrana basal (flecha negra pequeña). PAS 200x.

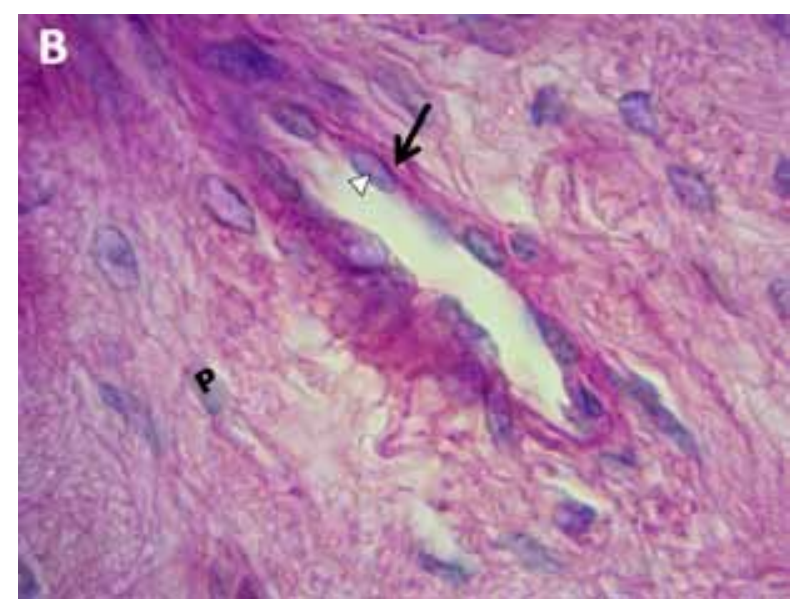

Figura B. Porción de lámina dérmica primaria $(\mathrm{P})$ de pie equino control. Se observa con mayor aumento la vénula, de paredes delgadas, endotelio normal (punta de flecha) y membrana basal conservada (flecha negra). PAS 400x.

ellos aparentaban no estar rodeados por citoplasma, lo cual permite hace inferir la posibilidad de que no solo haya existido desprendimiento, sino también ruptura de la membrana celular como producto de un proceso apoptótico.

La alteración de la morfología nuclear fue repetitiva en la túnica media de los vasos, en la cual pudo apreciarse, además, la separación de las fibras colágenas que la componen, evidenciable por la aparición de espacios blancos entre las mismas. Las metaarteriolas presentaban disrupción de la pared vascular, evidenciándose separación de las capas que forman su túnica media, con macrocariosis endotelial.

Las vénulas observadas a través de esta técnica mostraron los daños ya mencionados para las arteriolas y metaarteriolas en su túnica íntima, manifestándose 


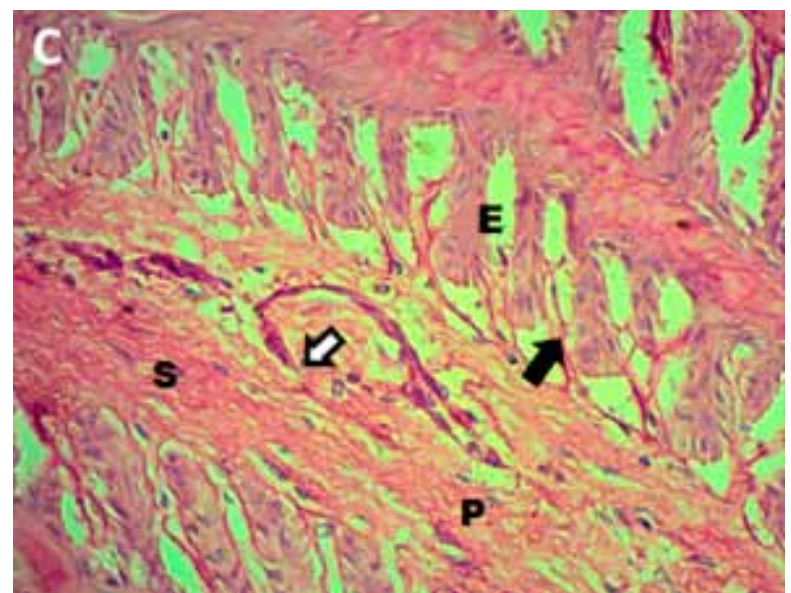

Figura C. Corte de unión dermo-epidérmica de pie equino tratado. Se observa separación entre láminas dérmicas secundarias $(\mathrm{S})$ y láminas epidérmicas secundarias (E), con desprendimiento y ruptura de la membrana basal (flecha negra). Nótese la disrupción del tejido colágeno en lámina dérmica primaria $(\mathrm{P})$ y la presencia de una vénula con pérdida de la continuidad de la membrana basal (flecha blanca). PAS 400x.

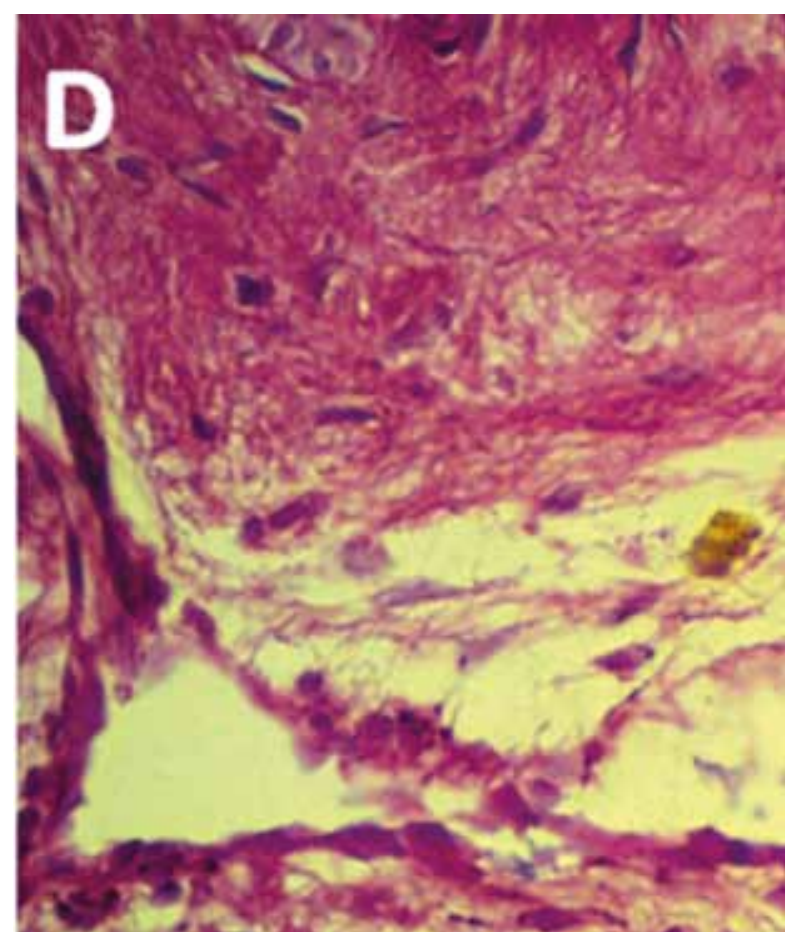

además la ruptura de la pared vascular. En los vasos venosos fue fácilmente apreciable el conjunto de lesiones antes mencionadas, particularmente en lo que respecta a la túnica íntima vascular, dado que presentaban un diámetro de luz considerable, que permitía su análisis detallado. La técnica de PAS permitió puntualizar la localización de daño a nivel de la membrana basal de las células endoteliales de todos los vasos sanguíneos estudiados (Figuras C y D).

Miscroscopía electrónica. La técnica de transmisión permitió observar con detalle el núcleo celular, que presentaba forma y tamaño normal, con eje longitudinal mayor al transversal, cromatina de aspecto normal y membrana nuclear intacta. El citoplasma reveló características normales, distinguiéndose mitocondrias con electrodensidad normal. En el citosol se observó además la presencia de numerosas vesículas pinocíticas, características de las células endoteliales; las mismas presentaban tamaño regular y distribución homogénea. Las células que formaban parte del endotelio presentaban uniones normales entre ellas y la membrana basal, manteniéndose la integridad y continuidad de esta última (Figura E).

En las muestras tratadas se detectó desprendimiento de células endoteliales que se hallaban dentro de la luz de los vasos sanguíneos; sumado a esto se logró

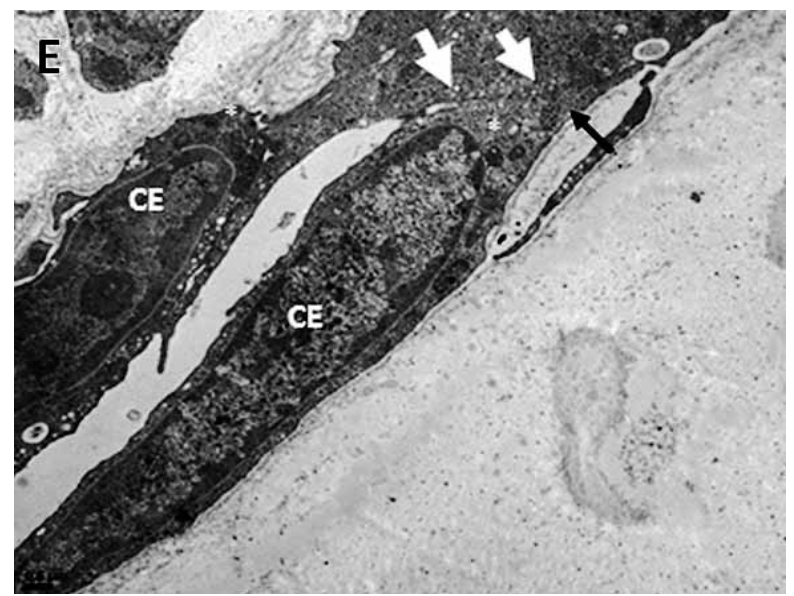

Figura E. Corte longitudinal de un vaso sanguíneo de la dermis de pie equino control. Se observan células endoteliales de forma y tamaño normal (CE). La lámina basal presenta integridad y continuidad (flechas negras). Las uniones intercelulares revelan integridad (flechas blancas). MET 15000x.

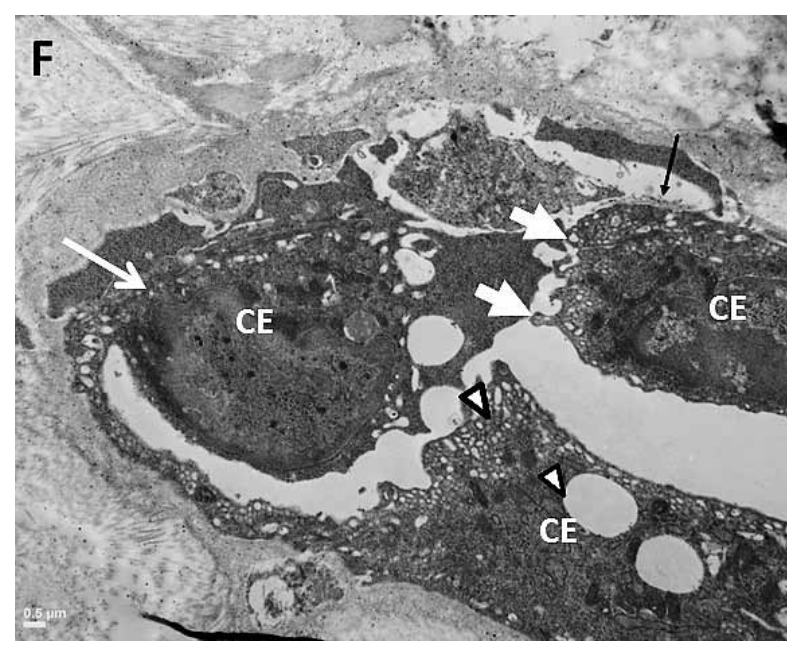

Figura F. Corte longitudinal de un vaso sanguíneo en equino tratado. Se observan células endoteliales aumentadas de tamaño (CE), cuyas láminas basales evidencian discontinuidad y sectores con desprendimientos (flecha negra delgada). Los núcleos endoteliales (aumentados) muestran numerosas indentaciones (flecha blanca delgada). Notese la presencia de vesículas pinocíticas (puntas de flechas) y la separación de las uniones intercelulares (flechas blancas anchas). MET 15000x. 
identificar falta de continuidad en la pared vascular. Las células endoteliales se presentaron aumentadas de tamaño, con lámina basal discontinua, mostrando sectores con desprendimiento de su unión a las células endoteliales.

Los núcleos endoteliales presentaron anisocariosis y macrocariosis. Las mitocondrias destacaban en el citoplasma ubicadas en puntos determinados del mismo, con aumento de la electrodensidad. Las vesículas pinocíticas citoplasmáticas mostraban tamaño variable, con distribución irregular, agrupándose en forma más densa en algunos sectores y ausentes en otros. Las uniones intercelulares estaban alteradas, revelándose separación entre células adyacentes (Figura F).

\section{DISCUSIÓN}

Este trabajo revela la utilidad de la biopsia del pie equino -como cultivo primario- para el estudio de las alteraciones de la red vascular inducida por toxinas de veneno de serpiente. El modelo experimental constituye una herramienta valiosa considerando que la toma de muestra (biopsia), no afecta la salud del equino, quien sufre una pequeña herida que no causa ningún trastorno dado que el material obtenido es reducido. Las lesiones observadas fueron repetitivas en todas las muestras estudiadas.

Estudios anteriores demostraron que la hemorragia desencadenada por el veneno de vipéridos es inducida por las metaloproteinasas del veneno de serpientes, siendo las vénulas y capilares los vasos más afectados ${ }^{6}$ , como se observó en este trabajo sumando las lesiones observadas en arteriolas y metarteriolas.

Estudios realizados con jararhagina, una metaloproteinasa aislada del veneno de $B$. jararaca, determinaron que la hemorragia inducida era el resultado de diferentes actividades tales como la degradación de proteínas de la matriz subendotelial, que causa disrupción del endotelio vascular, interfirienro también con la agregación y la adhesión plaquetaria mediadas por colágeno ${ }^{10}$. Otros autores demostraron que también inducen a apoptosis de células endoteliales ${ }^{26}$.

Se ha comprobado que las metaloproteinasas aisladas de venenos de serpientes, inhiben indirectamente la proliferación celular por liberación de componentes similares a angiostatina ${ }^{25}$, una enzima derivada de la degradación del plasminógeno, que tiene acción antiangiogénica, lo cual limitaría lo señalado ut supra, así como también la consecuentemente regeneración tisular. Los efectos hasta aquí mencionados son secuelas que ocurren in vivo.

Sin embargo, las metaloproteinasas de venenos de serpiente, son capaces de inducir la apoptosis de células endoteliales en ensayos in vitro. De igual manera, varios autores revelaron la habilidad de estas enzimas para hidrolizar varios componentes de la membrana basal in vitro ${ }^{3}$, resultados coincidentes con los obtenidos en este trabajo.
Se han aislado y caracterizado parcialmente varias metaloproteinasas hemorrágicas del veneno de Bothrops asper, la principal serpiente venenosa en la región centroamericana. Tales estudios permitieron proponer la hipótesis que estas enzimas, que son metaloproteinasas dependientes de zinc, hidrolizan algunas proteínas que componen la lámina basal que rodea las células endoteliales de los vasos capilares y de las vénulas ${ }^{2}$, lo cual ha sido documentado para otras especies de serpientes en ensayos in vitro ${ }^{14,23}$. La necrosis y muerte de células endoteliales fue ampliamente acreditada en ensayos in vitro ${ }^{2}$.

El hallazgo del desprendimiento de células endoteliales de la membrana basal reportado en este trabajo, tiene antecedentes en las producciones de otros autores que estudiaron el efecto de metaloproteinasas de vipéridos, determinando que estos componentes de los venenos interfiere con las moléculas de adhesión entre células endoteliales y la matríz extracelular, afectando la organización de filamentos de actina y fibras de estrés, las cuales culminan en muerte celular por apoptosis ${ }^{4,26}$.

Concluyendo, los hallazgos ultraestructurales revelados por la microscopía electrónica de transmisión fueron variados, incluyendo ruptura de la unión intercelular, modificación de la electrodensidad y aparición de indentaciones que deformaron el núcleo, aumentaron el tamaño y electrodensidad mitocondrial y disminuyeron el número de vesículas citoplasmáticas pinocíticas, en coincidencia con los resultados encontrados en ensayos in vivo con veneno entero de Bothrops jararacussu $^{24}$.

Agradecimientos. A la Prof. Dra. Ofelia Acosta de Pérez por su valiosa colaboración en la revisión del trabajo. A la Directora del CEPSAN Lic. Laura Rey, por donar el veneno de Bothrops diporus para la realización del estudio.

\section{REFERENCIAS}

1. Bailey SR, Adair HS, Reinemeyer CR, Morgan SJ, Brooks AC. 2009. Plasma concentrations of endotoxin and platelet activation in the developmental stage of oligofructose-induced laminitis. Vet Immunol \& Immunopathol 129: 167-173.

2. Baldo C, Jamora C, Yamanouye N, Zorn TM, Moura AM. 2010. Mechanisms of vascular damage by hemorrhagic snake venom metalloproteinases: tissue distribution and in situ hydrolysis. 2010. Plos Negl Trop Dis 29: 727.

3. Baramova EN, Shannon JD, Fox JW, Bjarnason JB. 1991. Proteolytic digestion of non-collagenous basement membrane proteins by the hemorrhagic metalloproteinase Ht-e from Crotalus atrox venom. Biomed Biochim Acta 50: 763-768.

4. Díaz C, Valverde L, Brenes O, Rucavado A, Gutierrez JM. 2005. Characterization of events associated with apoptosis/anoikis induced by snake venom metalloproteinase BaP1 on human endothelial cells. $J$ Cell Biochem 94: 520-528. 
5. Dickinson CE, Traut JL, Dragatz DA, Bennett DG, Knight AP. 1996. Rattlesnake venom poisoning in horses: 32 cases. J Am Vet Med Assoc 208: 1866-1871.

6. Escalante T, Shannon JD, Moura AM, Gutiérrez JM, Fox JW. 2006. Novel insights into capillary vessel basement membrane damage by snake venom hemorrhagic metalloproteinases: a biochemical and immunocytochemical study. Arch Biochem Biophys 455: 144-153.

7. Escalante T, Rucavado A, Fox JW, Gutiérrez JM. 2011. Key events in microvascular damage induced by snake venom hemorrhagic metalloproteinases. J Proteom 74 : 1781-1794.

8. García-Denegri ME. 2011. Aislamiento y caracterización de fosfolipasa $\left(\mathrm{PLA}_{2}\right.$ ) del veneno de Bothrops alternatus (víbora de la cruz) del nordeste argentino. Tesis Doctoral, Universidad Nacional de Córdoba (Argentina), p. 33-44.

9. Gutiérrez JM, Rucavado A. 2000. Snake venom metalloproteinases: their role in the pathogenesis of the local tissue damage. Biochimie 82: 841-850.

10. Kamiguti AS, Hay CR, Zuzel M. 1996. Inhibition of collagen-induced platelet aggregation as the result of cleavage of alpha 2 beta 1-integrin by the snake venom metalloproteinase jararhagin. Biochem J 320: 635-641.

11. Laing GD, Moura A. 2005. Jararhagin and its multiple effects on hemostasis. Toxicon 15: 987-996.

12. McGowan C. 2008. The role of insulin in endocrinopathic laminitis. J Eq Vet Sci 28: 603-607.

13. Molyneux GS, Haller CJ, Mogg K, Pollitt CC. 1994. The structure, innervations and location of arteriovenous anastomoses in the equine foot. Equine Vet. J 26: 305-312.

14. Oliveira AK, Paes AF, Asega AF, Camargo AC, Fox JW, Serrano SM. 2010. New insights into the structural elements involved in the skin haemorrhage induced by snake venom metalloproteinases. Thromb Haemost 104: 485-497.

15. Paes FO, Bonna FA, De Marval CA, Xavier SH, Santos RL, Faleiros RR, Alves GE. 2010. Histopatologia das lâminas do casco de equinos com laminite aguda induzida e tratados com ketoprofeno, fenilbutazona e flunixin meglumine. Arq Bras Med Vet Zoot 62: 241-250.
16. Pollitt CC, Molyneux GS. 1990. A scanning electron microscopical study of the dermal microcirculation of the equine foot. Equine Vet J 22: 79-87.

17. Pollitt CC. 1996. Basement membrane pathology: a feature of acute equine laminitis. Equine Vet J 28: 38-46.

18. Pollitt CC. 1998a. The anatomy and physiology of the hoof wall. Equine Vet Educ 10: 318-325.

19. Pollitt CC. 1998b. El pie del caballo, Ed. Harcourt-Brace, Madrid, España, 208 p.

20. Pollitt CC, Davis CT. 1998c. Equine laminitis: its development coincides with increased sublamellar blood flow. Equine Vet. J 26: 125-132.

21. Pollitt CC. 2004. Anatomy and physiology of the inner hoof wall. J Clin Techn Eq Pract 3: 3-21.

22. Ruíz RM, Ulon SN, Sario HM. 2004. Epidemiología del accidente ofídico en la Provincia de Corrientes. Sesión Comunic Cientif UNNE (Corrientes, Argentina), V-029. http://www.unne.edu.ar/unnevieja/Web/cyt/com2004/index.htm

23. Sanchez EF, Schneider SF, Yarleque A, et al. 2010. The novel metalloproteinase atroxlysin-I from peruvian $\mathrm{Bo}$ throps atrox (jergón) snake venom acts both on blood vessel ECM and platelets. Arch Biochem Biophys 496: 9-20.

24. Santo H, Marques MJ. 2005. Microvessel damage by $B$. jararacussu snake venom: pathogenesis and influence on muscle regeneration. Toxicon 46: 814-819.

25. Serrano SM, Jia LG, Wang D, Shannon JD, Fox JW. 2005. Function of the cysteine-rich domain of the hemorrhagic metalloproteinase atrolysin-A: targeting adhesion proteins collagen I and von Willebrand factor. Biochem $J$ 391: 69-76.

26. Tanjoni I, Weinlich R, Della-Casa MS, Clissa PB, Saldanha RF, et al. 2005. Jararhagin, a snake venom toxin, induces a specialized form of apoptosis (anoikis) selective to endothelial cells. Apoptosis 10: 851-861.

27. Yathirai S, Ramachandran CT. 1992. Snakebite in equines, a review. Centaur 8: 53-60. 